\title{
NARRATIVAS EMERGENTES NO ENSINO MÉDIO: DIREITOS HUMANOS \& EDUCAÇÃO
}

\author{
E. M. N. DIÓGENES ${ }^{1}$ e F. A. de Andrade ${ }^{2}$ \\ ${ }^{1}$ Universidade Federal de Alagoas - Centro de Educação \\ ${ }^{2}$ Universidade Federal do Ceará - Faculdade de Educação \\ E-mail: elionend@uol.com.br ${ }^{1}$ - andrade.ari@hotmail.com ${ }^{2}$
}

Artigo submetido em fevereiro/2012 e aceito em agosto/2013

\section{RESUMO}

Com este artigo adentramos o campo dos Direitos Humanos relacionado à educação de nível médio. Aqui, temos um relato de experiência concernente a um projeto de extensão intitulado "Formação Continuada em Direitos Humanos para Professores do Ensino Médio" que foi finalizado este ano. Este objetivava introduzir a temática dos direitos humanos no campo educacional em Alagoas, mais especificamente em Maceió, cidade reconhecidamente problemática quanto se trata da garantia mínima dos direitos dos cidadãos e cidadãs que a habitam. Para tanto, o projeto foi desenvolvido no interior de uma escola pública de ensino médio e envolveu uma formação em serviço para professores deste nível de educação básica, durante todo o ano de 2010 e parte de 2011 (maio). Assim, neste artigo fazemos três abordagens importantes: na primeira, tratamos dos fundamentos históricos e políticos da Educação em Direitos Humanos no Brasil. Na segunda, discorremos sobre a metodologia do projeto e seus resultados; e, na terceira: apontamos os desafios e possibilidades para quem enfrenta a difícil tarefa de tratar dessa temática no interior da sala de aula do ensino médio como "saber" e não como "caridade".

PALAVRAS-CHAVE: Ensino Médio, Direitos Humanos, Educação em Direitos Humanos.

\section{EMERGING NARRATIVES IN HIGH SCHOOL: EDUCATION \& HUMAN RIGHTS}

\section{ABSTRACT}

With this article we enter the field of Human Rights related to secondary education. Here we have an experience report concerning an extension project entitled "Continuing Education in Human Rights for Middle School Teachers" which was finalized this year. This aimed to introduce the theme of human rights in the educational field in Alagoas, Maceió more specifically, a city known problematic as it is the minimum guarantee of the rights of citizens who inhabit it. To this end, the project was developed within a public school high school and involved an in-service training for teachers of this level of basic education throughout the years of 2010 and part of 2011 (May). So in this article do three major approaches: the first deal of historical and political foundations of Human Rights Education in Brazil. On Monday, we discussed the project methodology and results, and the third: point out the challenges and possibilities for those facing the difficult task of dealing with this issue within the classroom of the school as "knowing" rather than "charity".

KEYWORDS: High School, Human Rights, Human Rights Education. 


\section{NARRATIVAS EMERGENTES NO ENSINO MÉDIO: DIREITOS HUMANOS \& EDUCAÇÃO}

\section{PALAVRAS PRIMEIRAS: A ENUNCIAÇÃO DO TEMA}

Direitos Humanos é uma expressão que assusta! Esta é uma experiência no campo do conhecimento que vamos levar para as nossas vidas, em se tratando de discutir direitos humanos na escola pública em Maceió, capital de Alagoas, estado pobre do Nordeste, mas com uma das mais poderosas economias da atualidade. O projeto de extensão que desenvolvemos na Universidade Federal de Alagoas (UFAL) ao longo de 2010 até meados de 2011 (maio) trata de uma formação continuada para professores do ensino médio.

O projeto intitulado "Formação Continuada em Direitos Humanos para Professores do Ensino Médio" tem uma filosofia bem simples: introduzir a questão dos direitos humanos em sala de aula. Assim, o objetivo central foi exatamente este: debater em curso de formação voltado para professores a possibilidade de introduzir os Direitos Humanos como tema gerador de conhecimentos em sala de aula. De tal modo, o primeiro passo foi conversar com os responsáveis pela escola sobre a possibilidade de realização de tal curso. Fomos bem recebidos e conseguimos matricular em torno de 30 professores. O curso foi desenvolvido em forma de encontros quinzenais na própria escola onde debatíamos questões relacionadas com três perspectivas: teórica, prática e pedagógica.

O curso foi particularmente inovador, vez que não trouxemos fórmulas e receitas de como se trabalhar tal temática em sala de aula. Em verdade, estávamos juntamente com os professores aprendendo. É desta experiência que tratamos aqui sobre dois vieses: um; o da fundamentação teórica e, dois; o da narrativa enquanto suporte memoriográfico da aprendizagem. Neste caso, deparamo-nos com uma narrativa marcadamente subjetiva, posto que, também nos fizemos parte "aprendente" do projeto.

De toda forma alertamos para o fato de que, aqui, o leitor vai encontrar um relato emergente de uma vivência na área dos Direitos Humanos e Educação em Alagoas que merece no mínimo uma reflexão coletiva, visto que muitas são as singularidades históricas, culturais e sociais que atravessam e que compõem o tecido existencial das pessoas que moram e educam nessa parte do Brasil. Aqui, não há 'nada acabado' no sentido de que as coisas se cristalizaram sem permitir outros olhares e vozes, mas a compreensão que norteia este relato é exatamente esta: “(...) muita coisa em nossa experiência não pode ser pronunciada de forma acabada (...)" (GOETHE, 2007, p. 22).

\section{EDUCAÇÃO EM DIREITOS HUMANOS NO BRASIL}

A discussão acerca dos direitos humanos no Brasil do ponto de vista educacional é relativamente recente. Os primeiros movimentos para implantação de políticas que mirassem esta temática surgem em meados da década de 1990 com a criação de programas e planos de Direitos Humanos além da criação da Rede Nacional de Educação em Direitos Humanos em 1995.

Com a redemocratização ocorre uma retomada de discussões "esquecidas" no âmbito social onde ressurge com grande efervescência a temática dos direitos humanos. A retomada desta discussão passou a gerar atuações específicas de movimentos sociais apoiadas por 
organismos educacionais que resultaram em inúmeras ações para a promoção da Educação em Direitos Humanos.

Com o Estado brasileiro redemocratizado a temática dos direitos humanos passa a fazer parte das discussões coletivas. No âmbito internacional a II Conferência Internacional de Direitos Humanos em Viena realizada em 1993, teve fundamental importância para o avanço desta discussão, por firmar acordo "sobre a importância de que os Direitos Humanos passassem a ser conteúdo programático da ação dos Estados nacionais" (PNDH, 2010, p. 15). Para tanto se recomendou a formulação e implementação de Planos e Programas Nacionais de Direitos Humanos. Segundo Mendonça (2010) a Conferência de Viena propunha que os países membros organizassem

[...] processos educacionais capazes de promover a compreensão dos Direitos fundamentais do ser humano como forma eficaz ao enfrentamento das violações no campo dos direitos civis e políticos, econômicos, sociais, culturais e ambientais, bem como no combate à intolerância étnico-racial, religiosa, cultural, geracional, territorial, físico-individual, de gênero, de orientação sexual, de nacionalidade, de opção política, dentre outras. (MENDONÇA, 2010, p. 8).

A partir destas discussões em 1996 é lançado o Primeiro Plano Nacional de Direitos Humanos (PNDH) no Brasil, sendo este ampliado e revisado em 2002 resultando na segunda versão. Em 2008 a 11a Conferência Nacional dos Direitos Humanos que teve como objetivo central revisar e atualizar o PNDH-2 apresentou como resultado a última versão, publicada em 2010.

Com a instituição do Plano Nacional de Direitos Humanos pelo decreto 1904/96 de 13 de maio de 1996, o Brasil dá um importante passo na expansão desta discussão e é um dos primeiros países a seguir a determinações resultantes da Conferência de Viena. O PNDH do Brasil foi o primeiro lançado na América Latina e o terceiro do mundo sendo precedido apenas pelos planos da Austrália e Filipinas.

Em 2003 é criado o Comitê Nacional de Educação em Direitos Humanos e elaborado o Plano Nacional de Educação em Direitos Humanos (PNEDH) que defende que

[...] a educação em direitos humanos deve abarcar questões concernentes aos campos da educação formal, à escola, aos procedimentos pedagógicos, às agendas e instrumentos que possibilitem uma ação pedagógica conscientizadora e libertadora, voltada para o respeito e valorização da diversidade, aos conceitos de sustentabilidade e de formação da cidadania ativa. (PNEDH, 2006, p. 23).

A formulação do Plano Nacional de Educação em Direitos Humanos marca mais um passo do Brasil na implementação de políticas de que permitissem a construção de uma cultura de paz, de respeito à dignidade humana.

O Programa Nacional de Direitos Humanos, já na sua terceira versão, sistematiza as diretrizes nacionais que orientam a atuação do poder público no âmbito dos Direitos Humanos. Nesse sentido, o PNDH-3, organizado em seis eixos orientadores, subdividido em 25 diretrizes, 82 objetivos estratégicos e 521 ações programáticas, assume o compromisso de promoção e proteção dos direitos humanos, determinando o caminho a ser seguido.

Dentre os seis eixos orientadores do PNDH-3 $\circ \mathrm{V}$ ressalta a Educação e Cultura em Direitos Humanos, visando à "formação de nova mentalidade coletiva para o exercício da solidariedade, do respeito às diversidades e da tolerância". (PNDH-3, 2010, p. 150) sendo dividido em quatro diretrizes com objetivos estratégicos definidos. 
A Educação em Direitos Humanos, fundamental veículo na construção de uma sociedade igualitária pauta-se em mecanismos que articulam:

\begin{abstract}
a) a apreensão de conhecimentos historicamente construídos sobre direitos humanos e a sua relação com os contextos internacional, nacional, regional e local; b) a afirmação de valores, atitudes e práticas sociais que expressem a cultura dos Direitos Humanos em todos os espaços da sociedade; c) a formação de consciência cidadã capaz de se fazer presente os níveis cognitivo, social, ético e político; d) o desenvolvimento de processos metodológicos participativos e de construção coletiva, utilizando linguagens e materiais didáticos contextualizados; e) o fortalecimento de políticas que gerem ações e instrumentos em favor da promoção, da proteção e da defesa dos Direitos Humanos, bem como da reparação das violações. (idem).
\end{abstract}

O PNDH-3 articula-se com o Plano Nacional de Educação em Direitos Humanos (PNEDH) por estabelecer relações com a política nacional de Educação e Cultura em Direitos Humanos alicerçando as políticas a serem adotadas nas esferas nacional, estadual, distrital e municipal.

Os objetivos do PNEDH defendidos também no Programa se estendem em cinco grandes áreas, a saber: Na educação básica, possibilitando desde a infância a formação de sujeitos de direito, propondo mudanças curriculares que incluam a transversal e permanentemente discussões acerca dos Direitos Humanos; no Ensino Superior, incluindo a temática por meio de disciplinas, linhas de pesquisa, projetos de extensão; na educação não formal, propondo a inclusão da temática em programas de capacitação de lideranças comunitárias, em programas de qualificação profissional e outros, o foco central está em estabelecer um diálogo e parcerias com movimentos populares, sindicatos, igrejas, ONGs, clubes, entidades empresariais e demais instituições que desenvolvam atividades formativas; formação e educação continuada em Direitos Humanos, discutindo gênero, relações étnico-raciais e de orientação sexual, perpassando por todo o serviço público; e pelos meios de comunicação em massa, permitindo a construção de uma cultura nacional de respeito e proteção aos Direitos Humanos.

$\mathrm{O} V$ eixo do PNDH-3 está organizado em cinco diretrizes com objetivos determinados e ações programáticas. As diretrizes versam sobre a efetivação das diretrizes e dos princípios da política nacional de educação em direitos humanos para fortalecer a cultura de direitos; o fortalecimento dos princípios da democracia e dos direitos humanos nos sistemas de educação básica, nas instituições de ensino superior e nas instituições formadoras; o reconhecimento da educação não formal como espaço de defesa e promoção aos direitos humanos; a promoção da educação em direitos humanos no serviço público; a garantia de direito à comunicação democrática e o acesso a informação para a consolidação de uma cultura em direitos humanos.

\title{
3. FORMAÇÃO CONTINUADA EM DIREITOS HUMANOS PARA PROFESSORES DO ENSINO MÉDIO: a experiência fala
}

O projeto FORMAÇÃO CONTINUADA EM DIREITOS HUMANOS PARA PROFESSORES DO ENSINO MÉDIO, cuja narrativa travamos agora, foi aprovado pela Pró-Reitoria de Extensão (PROEX) ligada à Universidade Federal de Alagoas (UFAL) em maio de 2010, quando se iniciou; e, foi concluído em maio de 2011. Portanto, foi desenvolvido num período de um ano e um mês.

O projeto foi executado por uma professora do CEDU e um aluno bolsista do curso de Pedagogia. Foi firmada também uma parceria com o Assessoria em Direitos Humanos e Segurança Pública (AEDHESP) coordenado por uma professora do curso de Serviço Social da UFAL 
que desenvolve em Alagoas, o Projeto Capacitação de educadores da rede básica de ensino em Educação em Direitos Humanos, cujo objetivo é a “(...) promoção de mudanças no sistema educacional de ensino no sentido de implementar uma cultura de Direitos Humanos nas escolas por meio da capacitação de educadores, técnicos e gestores da rede básica de educação, lideranças comunitárias, profissionais das cinco áreas do Plano Nacional de Educação em Direitos Humanos".

Assim, a base metodológica do Projeto foi montada de duas formas: 1) por meio de entrevistas com os professores e de consulta aos arquivos da Secretaria de Educação e 2) formação continuada dirigida aos professores do ensino médio.

Deste modo, a extensão conecta-se intrinsecamente com a pesquisa. Ainda atuamos junto às instituições promotoras dos Direitos Humanos em Maceió e articulamos sua atuação com os objetivos do projeto. Os Direitos Humanos é uma temática por si instigante.

Deste modo, foi imprescindível a participação social dos principais envolvidos na temática: organizações e estabelecimentos de defesa dos Direitos Humanos - centros, sociedades, associações, comissões e conselhos. De tal modo, acreditamos que a articulação dialógica permeou todo o trabalho.

O corpo discente que na verdade são docentes foi imprescindível na execução desse projeto. Assim, o projeto teve como meta sine qua non incentivar a participação dos alunos de modo que os mesmos se sintam atraídos pela temática e a desenvolvam em sua sala de aula com autonomia.

A pesquisa-ação com base nas idéias de Michel Thiollent (2007) foi o nosso guia procedimental. Desde o primeiro momento da realização do projeto até o seu término a pesquisa-ação norteou todo o desenvolvimento das ações. Deste modo, por meio da pesquisaação promovemos a participação de todos os envolvidos no sentido de dar minimamente conta da complexidade do tema.

Assim, proporcionamos aos envolvidos no curso uma rara oportunidade de assumir seus pressupostos e discuti-los com base num entendimento coletivo. $O$ intuito foi: propiciar aos professores um entendimento de seus problemas para que eles possam percebê-los e levantar alternativas que vão ao encontro de seus interesses pedagógicos.

\subsection{Resultados e discussão}

Alagoas é reconhecidamente um estado que tem sérios problemas no que toca a questão educacional voltada para o nível médio de ensino. Conforme Acioli (2003) Alagoas é um estado em "decadente situação econômica (idem, p. 109).

Com relação ao ensino médio, o Estado enquanto poder público somente assumiu sua função para com o ensino médio a partir da década de 1990 em que teve um crescimento de $100 \%$ nas matrículas em relação às outras redes: "Apesar do crescimento de $100 \%$, observa-se que a rede estadual começa a apresentar um crescimento a partir do ano de 1998 (...)" (idem, p. 112).

Segundo o documento de Reestruturação e Expansão do Ensino Médio no Brasil (BRASILIA, 2008) a educação média é um direito humano formal essencial para consolidação dos 
valores e conhecimentos científicos construídos pela humanidade. Nesse sentido, estamos enfrentando desafios sérios no desenvolvimento do projeto.

Antes de explicitarmos os resultados é importante colocar que o projeto é inovador e que em sua fase de desenvolvimento encontrou resistências por parte dos professores. Isto foi o que nos apontou um questionário aplicado aos professores em duas escolas públicas de ensino médio de Maceió/AL.

As unidades escolares onde o projeto foi desenvolvido localizam-se em bairros periféricos de Maceió com problemas de violência, de tráfico de drogas e alto índice de criminalidade juvenil, a saber: Clima Bom e Santos Dumont que têm, juntos, uma população de 61.650 habitantes, conforme dados do Instituto de Brasileiro de Geografia e Estatística (IBGE, 2000).

As escolas atendem alunos e alunas de classe social baixa em sua maioria. Foram entrevistados 12 professores que têm nível superior e pudemos perceber que há um preconceito muito grande com relação a essa abordagem na sala de aula. Dos 12 professores entrevistados, $62 \%$ não têm qualquer conhecimento sobre tal temática. 58\% acham desnecessário discutir tal questão, pois favoreceria a marginalidade e $45 \%$ vêem com desconfiança tal temática.

A preocupação central de nosso projeto configurou-se em construir uma cultura favorável aos Direitos Humanos dentro das escolas, vez que essas são espaços de sociabilidade humana, que não raras vezes contribuem para o favorecimento ou não de uma prática pedagógica fundada na valorização da dignidade humana. Assim causou-nos perplexidade, o fato de muitos professores guardarem ressalvas quanto à temática. É importante deixar claro que os direitos humanos, dizem respeito antes de qualquer coisa à vida e ao direito a ela, de forma plena e saudável.

Uma das conseqüências sobre a falta de conhecimento dos próprios direitos é a impossibilidade de exercer o direito essencial que assinalou Hannah Arendt (1983): o direito a ter direitos. Os dados mostram que para a maior parte da população a democracia está reduzida a uma competição eleitoral.

A mídia conservadora consegue manipular a mentalidade dos professores de forma que não raro se expressam da seguinte forma: direitos humanos é coisa de bandido. Outra resposta interessante: deviam-se ensinar aos alunos os deveres e não os direitos. Apesar dessa resistência que entendemos ser fruto das distorções que o tema Direitos Humanos sofre na grande mídia compreendemos ser possível continuar com o projeto inclusive alargando-o para outras escolas.

Sabemos também que o poder público local não tem contribuído muito para reversão dessa situação, pois há uma crescente dicotomia entre o projeto político pedagógico da Secretaria de Educação e a realidade social do povo alagoano.

Há também uma ausência de políticas públicas voltadas para resolver as problemáticas da miséria e da situação de risco em que vive a grande maioria das crianças e dos adolescentes. Em suma, o nosso projeto tem demonstrado que há muito por fazer e poucos colaboradores. De todo modo, a escola é um espaço geofísico complexo e como tal precisa ser compreendida, pois, quem sabe a partir dela é possível transformar socialmente a dura realidade vivida?

\section{CONCLUSÃO: desafios em jogo}


A realização do projeto "Formação Continuada em Direitos Humanos para Professores do Ensino Médio" foi de suma importância no sentido de que tomamos conhecimento com uma realidade profundamente complexa no interior da escola pública alagoana, qual seja: a precariedade no que diz respeito às condições de trabalho dos docentes. Assim, a realidade nos instiga a entender que não podemos parar. Os Direitos Humanos é uma temática em construção! Tudo está ainda em caráter embrionário. Não é a realidade síntese de múltiplas determinações (Karl Marx, 1818-1883)? Para nós, sim. Essa só é compreensível por meio de infinitas aproximações cognoscitivas.

Por isso é preciso ter clareza de que não acabamos o projeto, apenas começamos! Igualmente, sabemos que se fazem necessárias duas abordagens ao longo desse processo. Primeira: implantação de políticas de educação no sentido de formar permanentemente os professores no campo dos Direitos Humanos, tornando essa temática o princípio pedagógico por excelência da ação educativa. Segunda: garantia do direito de todos os cidadãos a uma educação de qualidade seja em qual nível ou essa ou aquela modalidade.

Um amplo processo de garantia de direitos voltados especificamente para o campo educativo, com certeza, reverteria a atual condição de degradação humana a que está submetida considerável parcela da população alagoana. Pode ser utópico acreditar que isso pode ser possível. É que

Os 'fatos', a cada nova abordagem, se apresentam como produtos de relações históricas crescentemente complexas e mediatizadas, podendo ser contextualizadas de modo concreto e inseridos no movimento maior que os engendra. A pesquisa, portanto, procede por aproximações sucessivas ao real, agarrando a história dos processos simultaneamente às suas particulares internas. (PAULO NETTO, 2004, p. 58).

Deste modo acreditamos que, antes de tudo o conhecimento é fundamental. E o conhecimento sobre os Direitos Humanos é condição sine qua non para a conscientização em defesa dos mesmos.

Em certo sentido é impossível defender algo que eu não conheço que eu não sei onde e como se origina, que eu não tenho como válido socialmente e constituído como histórico. Daí que os professores entrevistados ao falarem que direitos humanos é coisa de bandido e que as vítimas não têm direitos estão nada menos nada mais que demonstrando desconhecimento de causa e do sentido da causa.

Por isto que a formação continuada aqui se coloca como essencial vez que nos cursos de graduação de professores não se aborda tal questão. De modo que a compreensão dos direitos humanos no tempo e no espaço vai desvelar a verdadeira face desses qual seja: que diz respeito ao estatuto da humanidade, da garantia da vida e do viver, do viver e do amar, do amar e do ser feliz em uma sociedade que sistematicamente atravessa com uma lança os direitos básicos como saúde, trabalho e educação.

O Estado Democrático de Direito no Brasil institucionalizou os Direitos Humanos, pelo menos em Lei. Agora, o que nos cabe? A defesa e a promoção dos mesmos. A vigilância cidadã no sentido de não permitir que se transforme essa conquista em uma conquista neutra, onde apenas subsiste o seu conteúdo em forma de retórica.

A nossa prática inicial nesse projeto demonstra que os direitos humanos é um desafio porque a realidade nossa é ainda desigual e profundamente aniquiladora dos Direitos Humanos. 
Não importa muito para as pessoas, no atual contexto de individualismo neoliberal, o que ocorre com o outro, pois em geral o outro é visto como um inimigo em potencial, pois é o concorrente de uma vaga, de um ponto comercial, de uma falsa concepção de mérito.

Nesse contexto, as cenas comuns assistidas, de forma assustadora, por todos são a negação dos direitos e o acirramento dos conflitos sociais, raciais e étnicos que provoca uma verdadeira guerra social institucionalizada.

É neste quadro que devemos e precisamos lutar pela vida e pelo direito de ter direitos seja em que circunstancia histórica vivamos. Assim, trata-se de manter-se uma inflexível prevenção no âmbito da cidadania para garantir a defesa e preservação da liberdade humana: essa palavra que o "sonho humano alimenta que não há ninguém que explique e ninguém que não entenda". Entretanto, é a liberdade um sonho? É a liberdade um fetiche? É a liberdade uma abstração? Pode ser que sim e acreditamos nisso, mais do que isto o ser humano almeja a liberdade para dela fazer sua bandeira em prol da dignidade humana que só será plenamente efetivada quando, enfim, os direitos humanos forem uma realidade universal.

\section{Referências}

1. ACIOLI, Adenize Costa. 0 poder público e a política de expansão do ensino médio em Alagoas: projeto escola jovem. Dissertação de Mestrado (Programa de Educação). Maceió, UFAL, 2003.

2. ARENDT, Hannah. A Condição Humana. Trad. de Roberto Raposo, Rio de Janeiro: Forense, 1983.

3. BRASIL. Educação e Cultura em Direitos Humanos. In: Programa Nacional de Direitos Humanos (PNDH-3). Secretaria de Direitos Humanos da presidência da República. rev. e atual. Brasília: SDH/PR, 2010.

4. _ Comitê Nacional de Educação em Direitos Humanos. Plano Nacional de Educação em Direitos Humanos. Brasília: Secretaria Especial dos Direitos Humanos; Ministério da Educação, Ministério da Justiça, UNESCO, 2006.

5. _. Ministério da Educação. Secretaria de Assuntos Estratégicos da Presidência da República. Reestruturação e Expansão do Ensino Médio do Brasil. (Gt Interministerial Instituído Pela Portaria №. 1189 de 05 de dezembro de 2007 e a Portaria №. 386 de 25 de Março de 2008).

6. GOETHE, Johann Wolfgang Von. Fausto - uma tragédia. Rio de Janeiro: Editora 34, 2007.

7. MENDONÇA, Erasto Fortes. Apresentação. In: Políticas e Fundamentos da Educação em Direitos Humanos. São Paulo: Cortez, 2010.

8. NETTO, José Paulo Marxismo impenitente: contribuição à história das idéias marxistas. São Paulo: Cortez, 2004.

9. THIOLLENT, Michel. A metodologia da pesquisa-ação. 15. ed. São Paulo: Cortez, 2007. 